\title{
Intraluminal Endovascular Coil Migration: A Rare Complication Post-Embolization of the Gastroduodenal Artery for a Previously Bleeding Duodenal Ulcer
}

\author{
Yassin Naga $^{1}$, Mahendran Jayaraj ${ }^{2}$, Yousif Elmofti ${ }^{2}$, Annie Hong ${ }^{2}$, Gordon Ohning ${ }^{2}$ \\ 1. Internal Medicine, University of Nevada Las Vegas School of Medicine, Las Vegas, USA 2. Gastroenterology, \\ University of Nevada Las Vegas School of Medicine, Las Vegas, USA
}

Corresponding author: Gordon Ohning, gordon.ohning@unlv.edu

\begin{abstract}
Transarterial angiographic embolization is a highly effective, safe treatment for non-variceal upper gastrointestinal bleeding refractory to endoscopic intervention. However, intraluminal coil migration is a possible complication. Coil migration, while usually a self-limiting process, can lead to significant rebleeding. In our case, a patient presented with a life-threatening duodenal ulcer hemorrhage, likely precipitated by intraluminal endovascular coil migration after a recent gastro-duodenal artery embolization. He was successfully managed without endoscopic coil removal and had no additional gastrointestinal bleeding. It is important for endoscopists to be aware of this complication and weigh the risks and benefits of coil removal.
\end{abstract}

Categories: Radiology, Gastroenterology

Keywords: upper gastrointestinal bleed, coil migration, upper endoscopy, duodenal ulcer, esophagogastroduodenoscopy (egd)

\section{Introduction}

Approximately $8 \%-15 \%$ of patients with a non-variceal upper gastrointestinal bleed (UGIB) have persistent bleeding despite endoscopic hemostatic intervention [1]. Transarterial angiographic embolization (TAE) plays an important role when endoscopic interventions have failed. It has also decreased the need for salvage surgery [2]. TAE has been shown to have high clinical and technical success rates [3]. Coil embolization specifically is a safe intervention with a low rate of complications, which includes perforation, artery dissection, and coil migration [3-4]. In most cases, coil migration does not lead to severe complications although it can cause rebleeding and bowel ischemia [5-7]. Herein, we report a rare case of spontaneous intraduodenal coil migration and excretion following a recent coil embolization due to a bleeding duodenal ulcer nine days prior to admission.

Review began 04/11/2021 Review ended 04/19/2021 Published 04/21/2021

\section{() Copyright 2021}

Naga et al. This is an open access article distributed under the terms of the Creative Commons Attribution License CC-BY 4.0., which permits unrestricted use, distribution, and reproduction in any medium, provided the original author and source are credited.

\section{Case Presentation}

A 68-year-old male with a history of recent hospitalization due to duodenal ulcer bleeding presented to the hospital in cardiac arrest. Cardiopulmonary resuscitation led to a return of spontaneous circulation. During intubation, blood was observed in the oropharynx and a large amount of bright red blood was noted upon placement of an orogastric tube. He was persistently hypotensive and required aggressive resuscitation with three units of packed red blood cells for initial hemoglobin of $5.2 \mathrm{~g} / \mathrm{dL}$. He underwent an urgent esophagogastroduodenoscopy (EGD), which demonstrated multiple, large, conjoined duodenal ulcers in a deformed duodenal bulb that extended into the descending duodenum. A profusely bleeding vessel was seen at the base of the proximal duodenal bulb ulcer (Forrest Class 1A). In addition, a luminal metal coil with an overlying clot and debris was visualized at the base of a more distal duodenal bulb ulcer that extended into the descending duodenum (Figure 1). Successful endoscopic hemostasis was achieved with epinephrine injection and multipolar electro-cautery application. A hemoclip was placed on the visible vessel to mark the location for the radiologist. The exposed metal coil was left in place, as the immediate pressing matter was hemostasis. Due to the likely involvement of the gastroduodenal artery and the high risk of rebleeding, Interventional Radiology was consulted. An angiogram was performed, and no evidence of active extravasation was identified. However, multiple small left gastric artery branches appeared to feed the previously bleeding proximal duodenal bulb ulcer (Forrest Class $1 \mathrm{~A}$ ) identified by the presence of a hemoclip. Detachable embolization coils were placed in two branches of the left gastric artery. The angiogram also demonstrated an existing embolization coil in the gastroduodenal artery with no distal flow. A review of medical records revealed that this was the metal coil deployed for a UGIB at an outside hospital nine days prior. This was the same metal coil seen during endoscopy after it extruded through the duodenal wall. A follow-up abdominal CT obtained four days after hemostasis was achieved for an evaluation of shock, which demonstrated a high-density metallic focus in the lumen of the rectum with significant stool burden (Figure 2). He did not experience recurrent episodes of UGIB prior to discharge. 


\section{Cureus}

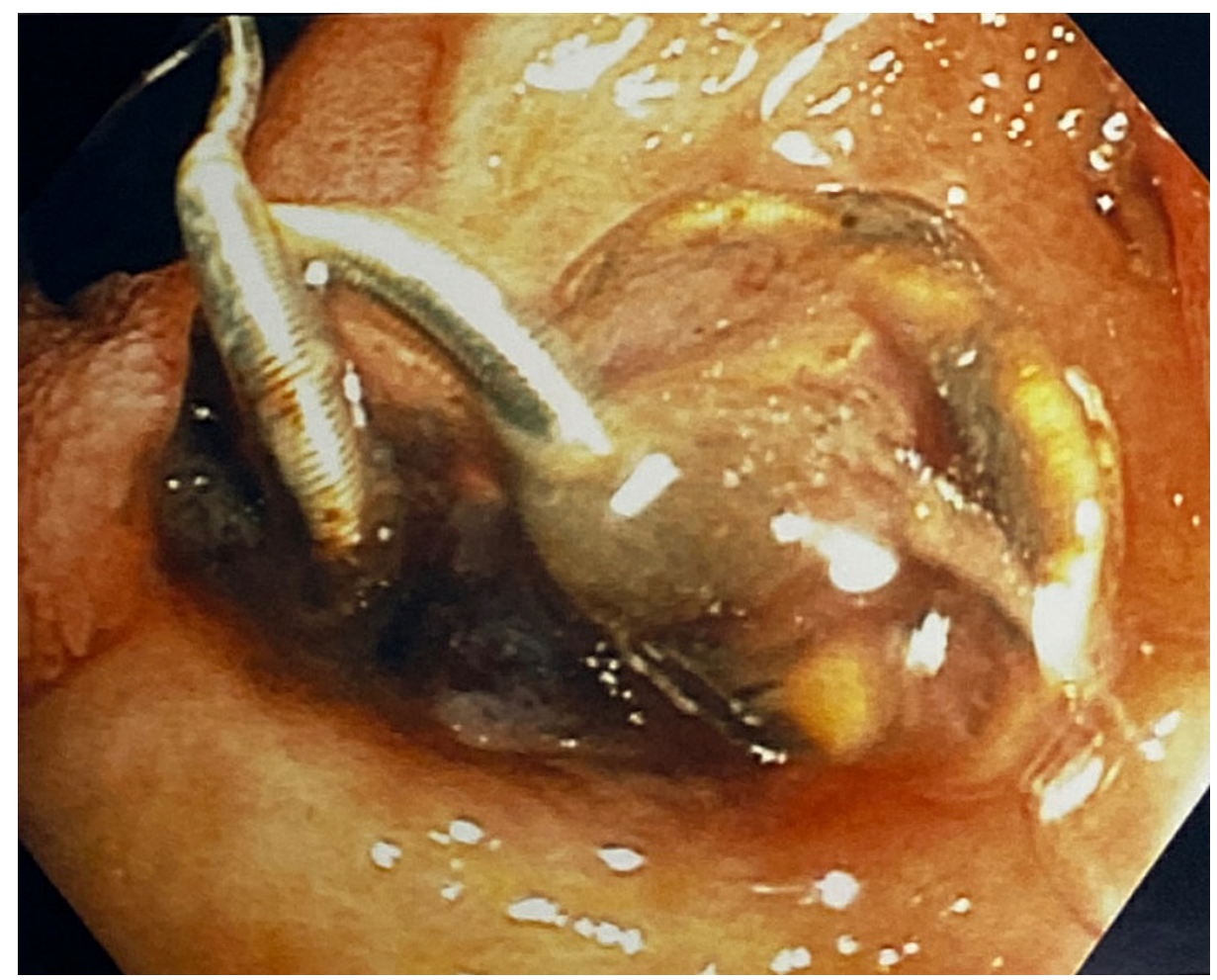

FIGURE 1: Esophagogastroduodenoscopy image of an unattached metal coil in the distal duodenal bulb ulcer

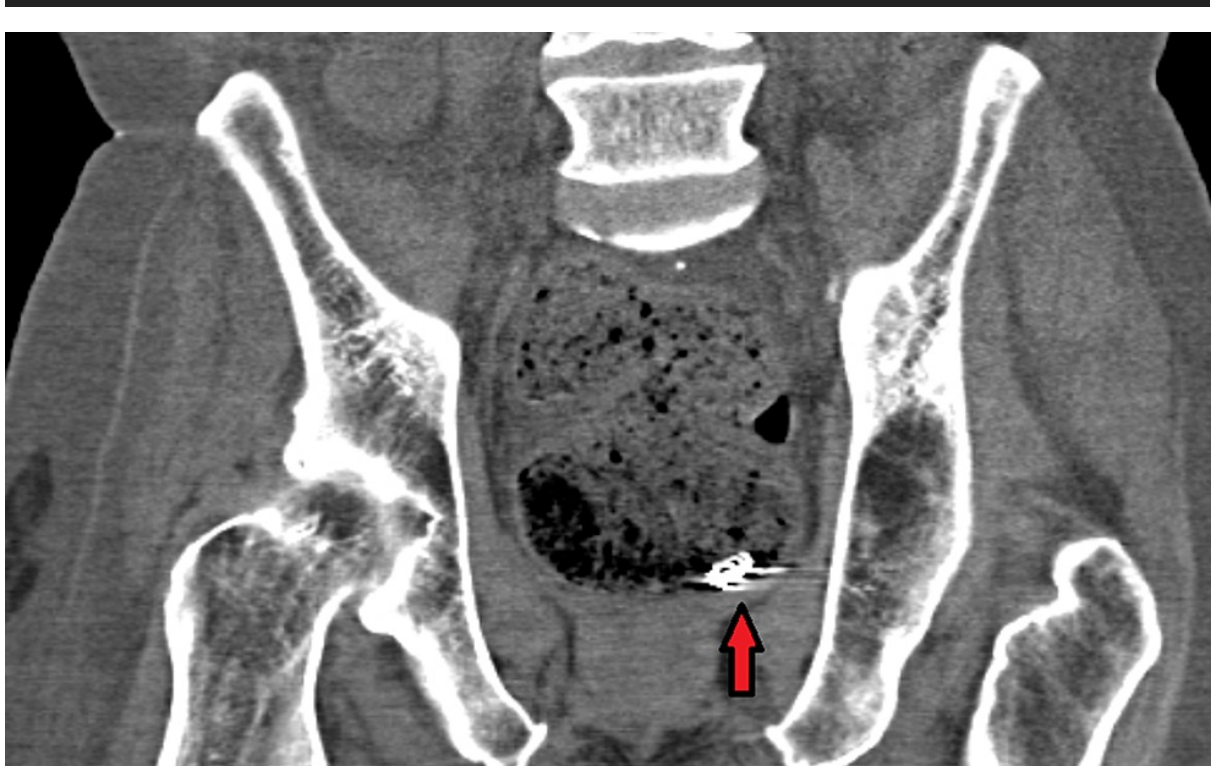

FIGURE 2: High-density focus in the rectal lumen suspected to be the migrated endovascular coil

\section{Discussion}

UGIB remains an important clinical challenge that carries significant morbidity and mortality rates. Endoscopic hemostatic intervention is the recommended first-line treatment [8]. Surgery and TAE are alternative therapies in patients with refractory bleeding despite endoscopic intervention. TAE is a highly effective intervention, as it allows for both diagnostic and therapeutic intervention. If the ulcer overlies the posterior duodenal bulb or lesser curvature of the stomach, it can lead to erosion of the gastroduodenal artery and left gastric artery, respectively. Our patient presented in cardiac arrest with hypovolemic shock due to a bleeding ulcer located at the posterior bulbar duodenum. He had undergone coil embolization of the 
gastroduodenal artery for another duodenal ulcer nine days prior. Multiple left gastric artery branches were responsible for this current GI bleed and were subsequently embolized after endoscopic hemostasis.

The overall technical and clinical success of TAE for non-variceal UGIB was reported in several studies as $92 \%-100 \%$ and $51 \%-94 \%$, respectively [9-12]. When compared to surgical intervention, TAE resulted in shorter hospital durations, fewer complications, and lower 30-day mortality [13-14]. Therefore, TAE is considered the first-line therapy for non-variceal UGIB refractory to endoscopic intervention. Several potential complications can arise from TAE, including access site hematomas (3\%-17\%), pseudoaneurysm, and coil migration (3\%) [15-17].

Intraluminal coil migration is a rare but notable complication of TAE that can occur immediately or several years later [16]. It is hypothesized that embolization of the feeding artery leads to ischemia, which allows for coil migration through the bowel wall [16]. In our patient, a displaced coil was seen on endoscopy at the time of intervention. He was subsequently found to have a metallic focus in the rectum on a CT abdomen obtained four days later, indicating coil detachment from the duodenal ulcer base and intraluminal migration out through the rectum. In most cases, coil migration is a self-limiting process without significant complications. However, it can lead to severe complications, including fatal rebleeding and bowel obstruction [16-18]. It is unclear whether our patient had rebleeding from coil migration itself or a separate ulcer invading the left gastric artery branches, but the onset of the bleed shortly after the TAE procedure and the finding of an embolization coil in the lumen within close proximity of the active bleeding suggests that migration of the coil was the precipitating event. In addition, CPR may have further displaced the migrated coil away from the bleeding ulcer base. The current management for migrated endovascular coils remains unclear. Several cases reported that migrated coils have spontaneously migrated through the rectum without any intervention, although this carries the risk of mucosal damage and rebleeding $[4,15]$. On the other hand, several cases have also reported on the successful removal of the migrated coils; however, bleeding remains a major risk that needs to be considered [18-20].

\section{Conclusions}

In conclusion, we report a rare case of a life-threatening recurrent UGIB caused by spontaneous intraluminal coil migration following recent gastroduodenal artery coil embolization. Although rare, it is an important complication that clinicians should be aware of. Currently, the management of migrated coils remains unclear and more research is necessary to help formulate guidelines.

\section{Additional Information \\ Disclosures}

Human subjects: Consent was obtained or waived by all participants in this study. Conflicts of interest: In compliance with the ICMJE uniform disclosure form, all authors declare the following: Payment/services info: All authors have declared that no financial support was received from any organization for the submitted work. Financial relationships: All authors have declared that they have no financial relationships at present or within the previous three years with any organizations that might have an interest in the submitted work. Other relationships: All authors have declared that there are no other relationships or activities that could appear to have influenced the submitted work.

\section{Acknowledgements}

Yassin Naga and Mahendran Jayaraj are co-first authors in this case report.

\section{References}

1. Laine L, McQuaid KR: Endoscopic therapy for bleeding ulcers: an evidence-based approach based on metaanalyses of randomized controlled trials. Clin Gastroenterol Hepatol. 2009, 7:33-47. 10.1016/j.cgh.2008.08.016

2. Lau LHS, Sung JIY: Treatment of upper gastrointestinal bleeding in 2020: new techniques and outcomes . Dig Endosc. 2021, 33:83-94. 10.1111/den.13674

3. Loffroy R, Rao P, Ota S, De Lin M, Kwak BK, Geschwind JF: Embolization of acute nonvariceal upper gastrointestinal hemorrhage resistant to endoscopic treatment: results and predictors of recurrent bleeding. Cardiovasc Intervent Radiol. 2010, 33:1088-100. 10.1007/s00270-010-9829-7

4. French B, Hayes D: Endovascular coil migration into the intestinal lumen: two cases of successful nonoperative management. Vasc Endovascular Surg. 2019, 53:157-9. 10.1177/1538574418805224

5. Singh G, Denyer M, Patel JV: Endoscopic visualization of embolization coil in a duodenal ulcer . Gastrointest Endosc. 2008, 67:351-2. 10.1016/j.gie.2007.08.022

6. Kuhara A, Koganemaru M, Ishikawa H, Abe T: Late-occurring coil migration into the duodenum. BMJ Case Rep. 2013, 2013:bcr2012007759. 10.1136/bcr-2012-007759

7. Jaurigue MM, Snyder M, Cannon M: Recurrent upper GI bleeding secondary to coil migration in a patient with known NSAID-induced peptic ulcer disease. Gastrointest Endosc. 2014, 79:1004. 10.1016/i.gie.2014.01.018

8. Barkun A, Bardou M, Marshall JK: Consensus recommendations for managing patients with nonvariceal upper gastrointestinal bleeding. Ann Intern Med. 2003, 139:843-57. 10.7326/0003-4819-139-10-200311180- 


\section{Cureus}

00012

9. Loffroy R, Guiu B, D'Athis P, et al.: Arterial embolotherapy for endoscopically unmanageable acute gastroduodenal hemorrhage: predictors of early rebleeding. Clin Gastroenterol Hepatol. 2009, 7:515-23. 10.1016/j.cgh.2009.02.003

10. Loffroy R, Guiu B, Cercueil JP, et al.: Refractory bleeding from gastroduodenal ulcers. Arterial embolization in high-operative-risk patients. J Clin Gastroenterol. 2008, 42:361-7. 10.1097/MCG.0b013e3180319177

11. Holme JB, Nielsen DT, Funch-Jensen P, Mortensen FV: Transcatheter arterial embolization in patients with bleeding duodenal ulcer: an alternative to surgery. Acta Radiol. 2006, 47:244-7. $10.1080 / 02841850600550690$

12. Larssen L, Moger T, Bjørnbeth BA, Lygren I, Kløw NE: Transcatheter arterial embolization in the management of bleeding duodenal ulcers: a 5.5-year retrospective study of treatment and outcome. Scand J Gastroenterol. 2008, 43:217-22. 10.1080/00365520701676443

13. Ramaswamy RS, Choi HW, Mouser HC, Narsinh KH, McCammack KC, Treesit T, Kinney TB: Role of interventional radiology in the management of acute gastrointestinal bleeding. World J Radiol. 2014, 6:8292. 10.4329/wjr.v6.i4.82

14. Lau JY, Barkun A, Fan DM, Kuipers EJ, Yang Y-S, Chan FKL: Challenges in the management of acute peptic ulcer bleeding. Lancet. 2013, 381:2033-43. 10.1016/S0140-6736(13)60596-6

15. Yap FY, Omene BO, Patel MN, et al.: Transcatheter embolotherapy for gastrointestinal bleeding: a single center review of safety, efficacy, and clinical outcomes. Dig Dis Sci. 2013, 58:1976-84. 10.1007/s10620-012 $2547-\mathrm{z}$

16. Kudaravalli P, Saleem SA, Pendela VS, Arif MO: Rare complication of interventional radiology-guided arterial embolization of the gastroduodenal artery in the setting of acute gastrointestinal bleed: migrated coils in the duodenum. Cureus. 2020, 12:e7365. 10.7759/cureus.7365

17. Choi CJ, Lim H, Kim DS, Jeong YS, Park SY, Kim JE: Massive duodenal bleeding after the migration of endovascular coils into the small bowel. Clin Endosc. 2019, 52:612-5. 10.5946/ce.2019.020

18. Hewgley WP, Webb DL, Garrett HE Jr: Migrated embolization coil causes intestinal obstruction . J Vasc Surg Cases Innov Tech. 2018, 4:8-11. 10.1016/j.jvscit.2017.11.001

19. Han YM, Lee JY, Choi IJ, et al.: Endoscopic removal of a migrated coil after embolization of a splenic pseudoaneurysm: a case report. Clin Endosc. 2014, 47:183-7. 10.5946/ce.2014.47.2.183

20. Natov NS, Uflacker AB, Shami VM: Endoscopic removal of migrated endovascular coils from the duodenum . VideoGIE. 2018, 3:249-51. 10.1016/j.vgie.2018.05.007 